\section{$\underset{\text { hommes }}{\text { \& migrations }}$}

\section{Hommes \& migrations}

Revue française de référence sur les dynamiques

migratoires

1302 | 2013

Le Japon, pays d'immigration?

\title{
Mathias Enard, Rue des voleurs
}

Paris, Actes Sud, 2012, 252 p., 21,50€

\section{Michaël Ferrier}

\section{Q OpenEdition \\ 1 Journals}

\section{Édition électronique}

URL : http://journals.openedition.org/hommesmigrations/2524

DOI : 10.4000/hommesmigrations.2524

ISSN : 2262-3353

\section{Éditeur}

Musée national de l'histoire de l'immigration

\section{Édition imprimée}

Date de publication : 1 avril 2013

Pagination : 189-190

ISBN : 978-2-919040-22-3

ISSN : $1142-852 X$

\section{Référence électronique}

Michaël Ferrier, « Mathias Enard, Rue des voleurs », Hommes \& migrations [En ligne], 1302 | 2013, mis en ligne le 17 septembre 2013, consulté le 22 septembre 2020. URL : http://journals.openedition.org/

hommesmigrations/2524; DOI : https://doi.org/10.4000/hommesmigrations.2524

Ce document a été généré automatiquement le 22 septembre 2020.

Tous droits réservés 


\title{
Mathias Enard, Rue des voleurs
}

\author{
Paris, Actes Sud, 2012, 252 p., 21,50€
}

\section{Michaël Ferrier}

\section{RÉFÉRENCE}

Mathias Enard, Rue des voleurs, Paris, Actes Sud, 2012, 252 p., 21,50€.

1 Dès le début, j'ai été pris par ce livre : Mathias Enard a un style, qui s'impose dès les toutes premières lignes. C'est rare. Ensuite, on peut ouvrir le roman à n'importe quelle page: tout de suite, la voix revient, caractéristique, inimitable. C'est un rythme particulier, avec une phrase parfois très longue et pourtant jamais pompeuse ou verbeuse. C'est une phrase en déplacement permanent, une phrase migrante, prenant appui sur une extraordinaire mécanique des points-virgules (Enard est un orfèvre du point-virgule, dans toutes ses nuances, dans toute son amplitude), et qui peut épouser aussi bien les sinuosités de la réflexion intérieure que la description d'un paysage de Barcelone ou de Tunis.

2 C'est aussi un livre courageux et intelligent. Courageux par son sujet, sujet brûlant qui aurait pu mener aux pires banalités ou, à l'inverse, aux pires extrémités (sur les printemps arabes, l'attentat de Marrakech, la tuerie de Toulouse, l'islam, le terrorisme). Intelligent par le choix des sites et des personnages, ainsi que par le traitement qu'il leur réserve: le choix de Tanger, par exemple, ville-frontière qui nous rappelle à chaque rue que le destin du monde arabe est le nôtre, et en même temps ville en marge, tout comme le beau personnage de Lakhdar, le narrateur, complexe et séduisant, narrateur-chien fou, tour à tour irritant, amusant, émouvant.

Roman plein de poésie également, pas de cette "poésie“ qui consiste à enrober les phrases avec de beaux adjectifs bien cousus et rutilants, mais d'une poésie pour ainsi dire interne, naissant de la syntaxe et du rythme autant que du vocabulaire et des images. La première phrase, par exemple, est époustouflante.

4 Enfin, c'est un livre loin des clichés, loin de l'ignorance phénoménale et de la bêtise qui s'empare des bouches et se pose sur les micros quand on aborde ces sujets. C'est un 
livre qui maîtrise parfaitement son projet, avec un humour à la fois féroce et fragile, un livre transpercé aussi par l'ironie et l'insolence, le tout servi par une langue superbe. Il faut le dire : par son sujet, par son style, par son ton, Rue des voleurs n'est pas seulement un bon ouvrage de plus sur l'exil, mais un grand livre qui sait nous arracher à nos certitudes, à nos indifférences ou à nos ignorances, pour nous faire entendre une voix singulière prise dans le tumulte du monde. C'est un livre fragile, parfois hilarant, souvent émouvant. Un livre vivant: "La vie est une machine à arracher l'être; elle nous dépouille, depuis l'enfance, pour nous repeupler en nous plongeant dans un bain de contacts, de voix, de messages qui nous modifient à l'infini, nous sommes en mouvement." 